\title{
Corticotropin releasing factor receptor antagonists: potential future therapy in gastroenterology?
}

\section{Y Taché}

\section{New corticotropin releasing factor (CRF) antagonists in irritable bowel disease (IBS) warrant testing, and $\mathrm{CRF}_{1}$ receptors may be a promising target for the treatment of IBS}

$\mathrm{R}$ ecent years have witnessed important developments in the understanding of the biochemical coding of stress. ${ }^{1}$ In addition to the 41 amino acid peptide, corticotropin releasing factor (CRF), novel mammalian CRF related peptides, urocortin 1 , urocortin 2 , and urocortin 3 have recently been discovered. ${ }^{2}$ These CRF ligands display distinct affinity to the two cloned G protein coupled CRF $1\left(\mathrm{CRF}_{1}\right)$ and 2 $\left(\mathrm{CRF}_{2}\right)$ receptors. ${ }^{1-3} \mathrm{CRF}$ has higher affinity for $\mathrm{CRF}_{1}$ than for $\mathrm{CRF}_{2}$ receptor, urocortin 1 displays equal affinity for both subtypes, and urocortin 2 and 3 have selective affinity for $\mathrm{CRF}_{2}$ receptor. ${ }^{23}$ In addition to the mapping of CRF ligands and receptors in the brain ${ }^{24}$ and gut $^{5-7}$ the development of potent selective $\mathrm{CRF}_{1}$ and $\mathrm{CRF}_{2}$ antagonists ${ }^{89}$ and generation of transgenic mouse models ${ }^{1}$ provided tremendous insight in the investigation of the underlying mechanisms of stress. Convergent studies established the role of the brain $\mathrm{CRF}_{-\mathrm{CRF}_{1}}$ pathways in mediating the endocrine, autonomic, behavioural, and visceral responses to stress ${ }^{131011}$ while $\mathrm{CRF}_{2}$ receptors may be important in dampening stress sensitivity. ${ }^{1}$

Extensive preclinical research effort has solidified the concept that overactivity in the brain $\mathrm{CRF}^{-\mathrm{CRF}_{1}}$ signalling system contributes to the onset of anxiety disorders and depression. ${ }^{12}$ These observations have spurred the development of a number of non-peptide $\mathrm{CRF}_{1}$ receptor antagonists which can readily cross the blood-brain barrier on peripheral administration. ${ }^{8}{ }^{9}$ These compounds prevent various stress related anxiogenic behaviours in rodents. ${ }^{13}$ Clinical studies in patients with major depression and post-traumatic disorders showed that CRF levels are elevated in the cerebrospinal fluid and lowered by effective antidepressants. ${ }^{12}$ In patients treated with interferon $\alpha$ for chronic hepatitis $\mathrm{C}$, activation of the brain CRF pathways induced by interferon- $\alpha^{14}$ is frequently associated with psychiatric side effects that have overlapping features with major depression..$^{15}$ In mice, synthetic recombinant type I interferon $\alpha$ induced a depressive-like behaviour that is abolished by pretreatment with the $\mathrm{CRF}_{1}$ receptor antagonist $\mathrm{CP}$ 154,526. ${ }^{16}$ A first phase II open label clinical trial including patients with major depressive disorders indicated that the $\mathrm{CRF}_{1}$ antagonist R121919 was effective in reducing depression and anxiety scores. ${ }^{17}$ Such beneficial effects were obtained at doses that neither disrupted normal circadian hypothalamic-pituitary axis hormone production nor hampered adrenal corticotrophic hormone (ACTH) or cortisol responses to CRF stimulation. ${ }^{17}$ Collectively, existing preclinical and clinical reports indicate that $\mathrm{CRF}_{1}$ antagonists may have therapeutic potential in the treatment of affective disorders. ${ }^{12} 13$

Available evidence suggests that the $\mathrm{CRF}_{1}$ receptor may also be an appealing target in the context of functional bowel disorders. ${ }^{18}$ Irritable bowel syndrome (IBS) is a common bowel disorder with clinical features that include recurrent abdominal pain or discomfort associated with altered bowel habits in the absence of structural pathology. ${ }^{19}$ In studies of hospital outpatients with IBS, it has been reported that symptoms or the chronic course of the illness can be exacerbated by psychosocial stressors. ${ }^{19} 20$ A high co-prevalence of IBS with psychiatric disorders, including anxiety and depression, is also well documented. ${ }^{19} 2122$ Other clinical studies showed that psychological factors predicted the occurrence of diarrhoea predominant IBS that develops in certain subgroups of patients that had acute gastroenteritis. ${ }^{19}$ The underlying mechanisms of such an association may be explained in the framework of overactivity of the $\mathrm{CRF}^{-C R F_{1}}$ signalling pathways. Evidence supporting this contention came from initial experimental demonstration of an interrelationship between activation of central $\mathrm{CRF}_{1}$ receptors and stress related induction of IBS-like symptoms. ${ }^{18}$ Administration of CRF and urocortin 1 into the lateral brain ventricle stimulated colonic motor function in rats, mice, and gerbils and increased abdominal pain to colorectal distension in rats. ${ }^{10}{ }^{23}$ Sites of action were located at a specific hypothalamic nucleus (paraventricular nucleus) or pontine area [locus coeruleus (LC), LC/Barrington nucleus $]^{10}$ that also induced CRF related behaviours symptomatic of anxiety and depression. ${ }^{124}$ Studies with a number of selective $\mathrm{CRF}_{1}$ antagonists (CP-154,526, CRA-1000, NBI-35965, or NBI-27914) injected intracerebroventricularly or peripherally blunted stress related anxiogenic behaviour, visceral hyperalgesia, and activation of colonic secretory and motor function in rodents and monkeys. ${ }^{10} 112325$ Moreover, female mice with deletion of the $\mathrm{CRF}_{1}$ receptor gene showed reduced anxiety-like behaviour and colonic motor response to the open field test. ${ }^{26}$ The colonic response to central CRF-CRF 1 pathway activation is unrelated to pituitary-adrenal hormone release and is mediated by modulation of the autonomic nervous system, particularly stimulation of sacral parasympathetic activity in rodents. ${ }^{10}$ There is also a decrease in vagal outflow to the upper gut and activation of the sympathetic nervous system that contribute to the concomitant inhibition of gastric and small intestinal motility. ${ }^{10} 27$ Interestingly, it has been found that colorectal distension activates LC activity through $\mathrm{CRF}^{-C_{R} F_{1}}$ pathways in rodents. ${ }^{28} 29$ The increased discharge rate of neurones in the LC induced by stress of psychological or visceral origin leads to widespread activation of noradrenergic projections to forebrain target sites implicated in arousal and attention. ${ }^{29}$ These mechanisms may underlay the reported stress induced altered perceptual thresholds to colorectal balloon distension and hyperreactivity to stress in IBS patients. ${ }^{30}$

In addition to the role of brain CRF$\mathrm{CRF}_{1}$ pathways, experimental studies have convincingly established peripheral stimulatory actions of CRF on colonic secretory and motor function and permeability. ${ }^{31}$ The peptide, injected peripherally, stimulates colonic motility, transit, secretion of mucus, prostaglandins, and ions, degranulates colonic mucosal mast cells and increases intestinal permeability to ions and macromolecules. ${ }^{31-34}$ A direct action of CRF at the enteric nervous system was established by the presence of $\mathrm{CRF}_{1}$ receptors on colonic myenteric neurones. ${ }^{5}$ It was also demonstrated that activation of myenteric neurones, increased colonic motility, and induction of diarrhoea induced 
by intraperitoneal injection of CRF were mediated by $\mathrm{CRF}_{1}$ receptors in rodents. ${ }^{34-36}$ The relevance of peripheral CRF receptors in the stress response was established by the use of the peptide CRF antagonist $\alpha$-helical $\mathrm{CRF}_{9-41}$ that has poor brain penetrance. This CRF antagonist injected peripherally inhibited restraint stress induced stimulation of colonic motor function, prevented mucosal mast cell degranulation, and blocked the increased colonic mucin and ionic secretion, and intestinal permeability to macromolecules in rats. ${ }^{313}$ Similar to animal models, intravenous administration of CRF increased colonic motility and abdominal pain in IBS patients and the response was higher compared with normal subjects. ${ }^{37}$ Other studies showed that the preferential $\mathrm{CRF}_{1}$ agonist ovine CRF lowered the stool threshold and sensation of discomfort to colonic distension in normal subjects. ${ }^{38}$ In this issue of Gut, Sagami and colleagues ${ }^{39}$ have built on this framework and report the dampening influence of intravenous injection of the CRF receptor antagonist $\alpha$-helical $\mathrm{CRF}_{9-41}$ on symptoms triggered by colonic tracking distension and electrical stimulation of the rectal mucosa in IBS diarrhoea predominant patients [see page 958]. In this study, the authors show that intravenous injection of $\alpha$-helical $\mathrm{CRF}_{9-41}$, given to subjects unaware of the timing of antagonist administration, blunts the exaggerated motility response in the sigmoid colon to electrical stimulation in IBS patients compared with normal subjects. They also report that the CRF antagonist reduces significantly abdominal pain and anxiety score without compromising pituitary release of ACTH. Because of the small number of subjects included in the study, this initial clinical investigation warrants replication in a larger group of IBS patients and further assessment using a placebo control group. However, these findings, put in the context of existing preclinical and clinical data, support the testing of new CRF antagonists, particularly more potent $\mathrm{CRF}_{1}$ antagonists, in IBS and the view that $\mathrm{CRF}_{1}$ receptors are a promising target for the treatment of IBS.

CRF receptors antagonists may also have value in some forms of gut inflammation. A number of studies in rodents and humans established that CRF, acting through $\mathrm{CRF}_{1}$ receptors, exerts an autocrine-paracrine proinflammatory action in peripheral tissues undergoing an inflammatory process. ${ }^{40}$ $\mathrm{CRF}$, urocortin 1 , and $\mathrm{CRF}_{1}$ receptors have been detected at both the gene and protein levels at sites of inflammation ${ }^{40}$ in the rodent and human intestine. ${ }^{41-43}$ Peripheral administration of $\mathrm{CRF}_{1}$ receptor antagonists significantly inhibit the degree of inflammation associated with an acute enterotoxic response, as monitored by the reduction in toxin $\mathrm{A}$ induced ileal secretion, epithelial cell damage, mucosal oedema, neutrophil infiltration, and mucosal content of interleukin $1 \beta$ and tumour necrosis factor $\alpha .^{43}$ This points to the potential use of specific $\mathrm{CRF}_{1}$ receptor antagonists in intestinal inflammatory conditions. In the upper gut, other potential clinical relevance of targeting $\mathrm{CRF}_{1}$ receptors has been recently reviewed in the context of cyclic vomiting syndrome ${ }^{27}$ and postoperative gastric ileus. ${ }^{44}$

In summary, a growing body of experimental evidence has demonstrated that $\mathrm{CRF}_{1}$ receptor antagonists alleviate the development of anxietylike behaviour and stress related alterations of gut function and enterotoxin mediated intestinal inflammation. The positive results associated with the use of CRF receptor antagonists in IBS patients reported in the present issue of Gut hold promise and warrant testing using selective $\mathrm{CRF}_{1}$ antagonists.

Gut 2004;53:919-921.

doi: $10.1136 /$ gut.2003.036400

Correspondence to: $\operatorname{Dr} Y$ Taché, CURE/ Digestive Diseases Research Center, Bldg 115, Room 117, VA Greater Los Angeles Health Care System, 1130 Wilshire Blvd, Los Angeles, CA 90073, USA; yTaché@ucla.edu

\section{REFERENCES}

1 Bale TL, Vale WW. CRF and CRF receptor: Role in stress responsivity and other behaviors. Annu Rev Pharmacol Toxicol 2004;44:525-57.

2 Hauger RL, Grigoriadis DE, Dallman MF, et al. International Union of Pharmacology. XXXVI. Current status of the nomenclature for receptors for corticotropin-releasing factor and their ligands. Pharmacol Rev 2003;55:21-6.

3 Grammatopoulos DK, Chrousos GP. Functional characteristics of $\mathrm{CRH}$ receptors and potential clinical applications of CRH-receptor antagonists. Trends Endocrinol Metab 2002;13:436-44.

4 Morin SM, Ling N, Liu XJ, et al. Differential distribution of urocortin- and corticotropinreleasing factor-like immunoreactivities in the rat brain. Neuroscience 1999:92:281-91.

5 Chatzaki E, Crowe PD, Wang L, et al. CRF receptor type 1 and 2 expression and anatomical distribution in the rat colon. $J$ Neurochem (in press).

6 Muramatsu Y, Fukushima K, lino K, et al. Urocortin and corticotropin-releasing factor receptor expression in the human colonic mucosa. Peptides 2000;21:1799-809.

7 Kawahito Y, Sano H, Kawata M, et al. Local secretion of corticotropin-releasing hormone by enterochromaffin cells in human colon. Gastroenterology 1994;106:859-65.

8 Zorrilla EP, Taché Y, Koob GF. Nibbling at CRF receptor control of feeding and gastrocolonic motility. Trends Pharmacol Sci 2003;24:421-7.

9 Heinrichs SC, De Souza EB, Schulteis G, et al. Brain penetrance, receptor occupancy and antistress in vivo efficacy of a small molecule corticotropin releasing factor type I receptor selective antagonist. Neuropsychopharmacology 2002; 27: 194-202

10 Taché Y, Martinez V, Million M, et al. Stress and the gastrointestinal tract III. Stress-related alterations of gut motor function: role of brain corticotropin-releasing factor receptors, Am J Physiol 2001;280:G173-7.
11 Habib KE, Weld KP, Rice KC, et al. Oral administration of a corticotropin-releasing hormone receptor antagonist significantly attenuates behavioral, neuroendocrine, and autonomic responses to stress in primates. Proc Natl Acad Sci U S A 2000;97:6079-84.

12 Keck ME, Holsboer F. Hyperactivity of CRH neuronal circuits as a target for therapeutic interventions in affective disorders. Peptides $2001 ; 22: 835-44$.

13 Kehne J, De Lombaert S. Non-peptidic CRF1 receptor antagonists for the treatment of anxiety, depression and stress disorders. Curr Drug Target CNS Neurol Disord 2002;1:467-93.

14 Capuron L, Raison CL, Musselman DL, et al. Association of exaggerated HPA axis response to the initial injection of interferon-alpha with development of depression during interferonalpha therapy. Am J Psychiatry 2003;160:1342-5

15 Malaguarnera $M$, Laurino A, Di F, et al. Neuropsychiatric effects and type of IFN-alpha in chronic hepatitis c. J Interferon Cytokine Res $2001 ; 21: 273-8$.

16 Yamano $M$, Yuki $\mathrm{H}$, Yasuda S, et al. Corticotropin-releasing hormone ${ }_{1}$ receptors mediate consensus interferon- $\alpha$ YM643-induced depression-like behavior in mice. J Pharmacol Exp Ther 2000;292:181-7.

17 Zobel AW, Nickel T, Kunzel HE, et al. Effects of the high-affinity corticotropin-releasing hormone receptor 1 antagonist R121919 in major depression: the first 20 patients treated. $J$ Psychiatr Res 2000;34:171-81.

18 Taché Y, Martinez V, Million M, et al. Role of corticotropin releasing factor receptor subtype 1 in stress-related functional colonic alterations: implications in irritable bowel syndrome. Eur J Surg 2002;168(suppl 587): 16-22.

19 Jones J, Boorman J, Cann P, et al. British Society of Gastroenterology guidelines for the management of the irritable bowel syndrome. Gut 2000;47(suppl 2):ii 1-19.

20 Mönnikes $\mathrm{H}$, Tebbe JJ, Hildebrandt $M$, et al. Role of stress in functional gastrointestinal disorders. Evidence for stress-induced alterations in gastrointestinal motility and sensitivity. Dig Dis 2001;19:201-11.

21 Lydiard RB. Irritable bowel syndrome, anxiety, and depression: what are the links? J Clin Psychiatry 2001;62(suppl 8):38-45.

22 Solmaz M, Kavuk I, Sayar K. Psychological factors in the irritable bowel syndrome. Eur J Med Res 2003;8:549-56.

23 Martinez V, Wang L, Rivier J, et al. Central CRF, urocortins and stress increase colonic transit via CRF1 receptors while activation of CRF2 receptors delays gastric transit in mice. J Physiol 2004; 556:221-34

24 Weiss JM, Stout JC, Aaron MF, et al. Depression and anxiety: role of the locus coeruleus and corticotropin-releasing factor. Brain Res Bull 1994;35:561-72.

25 Million M, Grigoriadis DE, Sullivan S, et al. A novel water-soluble selective $\mathrm{CRF}_{1}$ receptor antagonist, NBI 35965, blunts stress-induced visceral hyperalgesia and colonic motor function in rats. Brain Res 2003;985:32-42.

26 Bale TL, Picetti R, Contarino A, et al. Mice deficient for both corticotropin-releasing factor receptor 1 (CRFR1) and CRFR2 have an impaired stress response and display sexually dichotomous anxiety-like behavior. $J$ Neurosci 2002;22:193-9.

27 Taché Y. Cyclic vomiting syndrome: the corticotropin-releasing-factor hypothesis. Dig Dis Sci 1999;44:79-86S

28 Lechner SM, Curtis aL, Brons R, et al. Locus coeruleus activation by colon distention: role of corticotropin-releasing factor and excitatory amino acids. Brain Res 1997;756:114-24.

29 Lejeune F, Millan MJ. The CRF1 receptor antagonist, DMP695, abolishes activation of locus coeruleus noradrenergic neurones by CRF in anesthetized rats. Eur J Pharmacol 2003:464: 127-33

30 Dickhaus B, Mayer EA, Firooz N, et al. Irritable bowel syndrome patients show enhanced modulation of visceral perception by auditory stress. Am J Gastroenterol 2003;98:135-43. 
31 Taché Y, Perdue MH. Role of peripheral CRF signaling pathways in stress-related alterations of gut motility and mucosal function. Neurogastroenterol Mot 2004;16(suppl 1): 1-6.

32 Castagliuolo I, Lamont JT, Qiu B, et al. Acute stress causes mucin release from rat colon: role of corticotropin releasing factor and mast cells. Am J Physiol 1996;271:G884-92.

33 Santos J, Saunders PR, Hanssen NPM, et al. Corticotropin-releasing hormone mimics stress induced rat colonic epithelial pathophysiology in the rat. Am J Physiol 1999;277:G391-9.

34 Maillot C, Million M, Wei JY, et al. Peripheral corticotropin-releasing factor and stressstimulated colonic motor activity involve type 1 receptor in rats. Gastroenterology 2000;119:1569-79.

35 Miampamba M, Maillot C, Million M, et al. Peripheral CRF activates myenteric neurons in the proximal colon through $\mathrm{CRF}_{1}$ receptor in conscious rats. Am J Physiol 2002;282:G857-65

36 Saunders PR, Maillot C, Million M, et al Peripheral corticotropin-releasing factor induces diarrhea in rats: role of $\mathrm{CRF}_{1}$ receptor in fecal watery excretion. Eur J Pharmacol 2002;435:231-5

37 Fukudo S, Nomura T, Hongo M. Impact of corticotropin-releasing hormone on gastrointestinal motility and adrenocorticotropic hormone in normal controls and patients with irritable bowel syndrome. Gut 1998:42:845-9.

38 Lembo T, Plourde V, Shui Z, et al. Effects of the corticotropin-releasing factor (CRF) on rectal afferent nerves in humans. Neurogastroenterol Motil 1996;8:9-18.

39 Sagami Y, Shimada Y, Tayama J, et al. Effect of a corticotropin releasing hormone receptor antagonist on colonic sensory and motor function in patients with irritable bowel syndrome. Gut 2004;53:958-64
40 Webster EL, Torpy DJ, Elenkov IJ, et al Corticotropin-releasing hormone and inflammation. Ann N Y Acad Sci 2001;840:21-32.

41 van Tol EA, Petrusz P, Lund PK, et al. Local production of corticotropin releasing hormone is increased in experimental intestinal inflammation in rats. Gut 1996;39:385-92.

42 Kawahito Y, Sano H, Mukai S, et al. Corticotropin releasing hormone in colonic mucosa in patients with ulcerative colitis. Gut 1995;37:544-51.

43 Wlk M, Wang CC, Venihaki $M$, et al. Corticotropin-releasing hormone antagonists possess anti-inflammatory effects in the mouse ileum. Gastroenterology 2002; 123:505-15

44 Luckey A, Wang L, Jamieson PM, et al. Corticotropin-releasing factor receptor 1-deficient mice do not develop postoperative gastric ileus. Gastroenterology 2003; 125:654-9.

\section{Leptin in intestinal inflammation: good and bad gut feelings}

G Matarese, R I Lechler

\section{Leptin has a the potent effect on T cell mediated intestinal autoimmunity and may have a role in the development of such diseases}

eptin, a molecule that is critical in the regulation of energy balance, body weight, and reproductive function, is a strong regulator of $\mathrm{T}$ cell function. ${ }^{1}$ This is one of many examples of redundancy and of the overlapping roles of molecules within the neuroendocrine and immune systems. ${ }^{2}$ Leptin is part of the helical cytokine family along with interleukin (IL-) 6, IL-12, and IL-15, its receptor (ObR) belonging to the group of class I cytokine receptors, which includes gp-130, the common signal transducing component for the IL-6 related family of cytokines. ${ }^{1}$ Leptin is expressed particularly in adipose tissue and to a lesser extent in other tissues such as muscle, stomach, and placenta. ${ }^{1}$ More recently, leptin has also been shown to be expressed in activated inflammatory $\mathrm{T}$ helper 1 lymphocytes during experimental autoimmune encephalomyelitis, an animal model of multiple sclerosis. ${ }^{3}$ In keeping with these findings, the ObR has been found not only on the hypothalamus and adipose tissue but also on immune cells such as $\mathrm{T}$ lymphocytes and monocytes. ${ }^{14}$ Addition of this hormone to $\mathrm{T}$ cells in culture can alter both their growth rate and pattern of production of cytokines-proteins that influence or mediate immune functions. ${ }^{45}$ Indeed, leptin enhances the activity of $\mathrm{T}$ cells that produce proinflammatory cytokines and that orchestrate many organ specific autoimmune diseases. ${ }^{45}$

In the current issue of Gut, Siegmund and colleagues ${ }^{6}$ describe the potent effects of leptin on $\mathrm{T}$ cell mediated intestinal autoimmunity and further define the role of leptin and its receptor in the development of such diseases [ see page 965]. The authors elegantly demonstrate that $\mathrm{T}$ cells from naturally leptin receptor deficient $(d b / d b)$ obese mice display a reduced capacity to induce, on passive transfer, a $\mathrm{T}$ cell mediated model of colitis in $\mathrm{T}$ cell deficient mice (scid mice). In this model, it is possible to study the function of leptin receptor deficient $\mathrm{T}$ cells in a normal microenvironment where insulin, glucocorticoids, and other factors are not altered as they are in $d b / d b$ obese mice. Leptin and its receptor were expressed on transferred wild-type (WT) T cells and infiltrating lymphocytes. Transfer of $\mathrm{T}$ cells from $d b / d b$ mice induced delayed disease compared with transfer of WT cells. Histological examination of the colon, early after induction of disease, revealed marked inflammation in mice injected with WT cells whereas no inflammation was observed in mice receiving $d b / d b$ cells. The delayed disease could not be attributed to the effect of increased levels of glucocorticoids in $d b / d b$ donor mice as treatment with glucocorticoids of WT donor lymphocytes did not change their pathogenic capacity. Lamina propria infiltrating lymphocytes (LPL) from WT and $d b / d b$ mice showed no difference in terms of differentiation, expression of homing receptors, or activation markers. Interestingly, the most evident difference was an increased rate of apoptosis of LPL derived from $d b / d b$ mice and reduced production of inflammatory cytokines and chemokines. Finally, the nuclear receptor peroxisome proliferator activated receptor $\gamma$ (PPAR $\gamma$ ), known to inhibit expression of inflammatory cytokines, including leptin, was highly expressed in colonic cells of mice that had received $d b / d b$ cells. ${ }^{6} 7$

Recent reports have shown that leptin secreted by the gastric mucosa is not fully degraded by proteolysis and can reach the intestine in an active form able to control the expression of sodium/ glucose and peptide transporters on intestinal epithelial cells. ${ }^{8}{ }^{9}$ Therefore, it may be speculated that leptin displays a dual nature: as a growth factor for the intestine, involved in the absorption of carbohydrates and proteins on the one hand, and as a mediator of the intestinal inflammation induced by $\mathrm{T}$ lymphocytes on the other. ${ }^{6-10}$ In addition, leptin deficient $o b / o b$ mice are resistant to a variety of experimental models of inflammation/autoimmunity. ${ }^{11-13}$ In particular, they are resistant to intestinal inflammation induced by administration of dextran sulphate sodium or trinitrobenzene sulphonic acid. $^{10}$ In these models, resistance to colitis in the absence of leptin was associated with reduced cytokine secretion and increased apoptosis of LPL. The report by Siegmund et al further reinforces the role of leptin and particularly its receptor in intestinal autoimmunity. ${ }^{6}$ It is well known that there are some confounding factors in animal models of leptin deficiency such as ob/ob and $d b / d b$ mice where massive obesity, insulin 
resistance, hyperglycaemia, and high levels of glucocorticoids could account for the altered immune response. ${ }^{15}$ In the present report, the model utilised elegantly rules out the possible influence on $\mathrm{T}$ cell pathogenicity of other factors, such as hyperglycaemia, hyperinsulinaemia, and hypercorticosteronaemia, that characterise $d b / d b$ mice.

Antagonists of the ObR may well be considered as possible agents able to alter the progression of intestinal inflammation. Recently, mesenteric adipose tissue from patients with Crohn's disease and ulcerative colitis showed high levels of expression of leptin mRNA. ${ }^{14}$ It is well known that food deprivation in the context of intestinal inflammation can improve disease symptoms and reduce the number of relapses. ${ }^{15}$ Many controlled trials in humans have shown that fasting and dietary change can ameliorate symptoms of patients with intestinal bowel disease, rheumatoid arthritis, and multiple sclerosis. ${ }^{3}{ }^{15-18}$ In view of the results of Siegmund et al, we must also consider whether fasting and changes in diet might change leptin levels, thus altering the function of $\mathrm{T}$ cells. The implication of this work is that the leptin/ObR axis drives the activity of proinflammatory, self-reactive $\mathrm{T}$ cells and that reduction in leptin secretion and/or in the ObR signalling machinery can change the pattern of cytokines generated and the disease inducing potential of intestinal $\mathrm{T}$ cells. The idea that leptin could also have a significant role in intestinal inflammation is strengthened by studies of the genes expressed in patients with intestinal bowel disease: leptin and related genes are overexpressed in both intestinal mucosa and mesenteric adipose tissue. ${ }^{14}$ Once again, we witness the remarkable choreography of molecules related to body weight and energy metabolism and the parallel roles of these same molecules in the finely tuned immune response. ${ }^{19}$ In the context of the whole animal, however, there is still much to understand about the potential interactions between fat, metabolism, and the immune response. Increasing experimental evidence is revealing the importance of molecules, including leptin, at the interface between the immune system and metabolic regulation. In a broader context, the work by Siegmund et al illustrates how the state of immunity is influenced by the presence of leptin whose serum levels correlate with nutritional status. Leptin enhances the transport of nutrients across the intestinal barrier and supports an immune response poised to repulse pathogens. ${ }^{589}$ But it may also represent a key substrate for the seed of autoimmunity to take root. Therefore, manipulation of the leptin/ObR axis may provide a novel means of downregulating $\mathrm{T}$ cell mediated autoimmune responses.

\section{ACKNOWLEDGEMENTS}

GM is supported by a Fondazione Italiana Sclerosi Multipla (FISM) Grant (No 2002/R/ 55) and Comitato Trenta Ore per la Vita, Mediaset, Milano, Italy.

Gut 2004;53:921-922.

doi: 10.1136/gut.2003.037283

\section{Authors' affiliations}

\section{G Matarese, Gruppo di}

ImmunoEndocrinologia, Istituto di

Endocrinologia ed Oncologia Sperimentale,

Consiglio Nazionale delle Ricerche (IEOS-

(NR), c/o Dipartimento di Biologia e

Patologia Cellulare e Molecolare, Università di Napoli "Federico II", Via S Pansini, 5-80131, Napoli, Italy

R I Lechler, Department of Immunology, Imperial College School of Medicine, Hammersmith Campus, London, UK

Correspondence to: Professor R I Lechler, Department of Immunology, Imperial College School of Medicine, Hammersmith Campus, Du Cane Road, London W12 ONN, UK; r.lechler@ imperial.ac.uk

\section{REFERENCES}

1 Friedman JM, Halaas JL. Leptin and the regulation of body weight in mammals. Nature 1998;395:763-70.

2 Steinman L. Connections between the immune system and nervous system. Proc Natl Acad Sci U S A 1993;90:7912-14.
3 Sanna V, Di Giacomo A, La Cava A, et al. Leptin surge precedes onset of autoimmune encephalomyelitis and correlates with development of pathogenic T cell responses. J Clin Invest 2003;111:241-50.

4 Fantuzzi G, Faggioni R. Leptin in the regulation of immunity, inflammation and hematopoiesis. $J$ Leukoc Biol 2000;68:437-46.

5 Lord GM, Matarese G, Howard JK, et al. Leptin modulates the T-cell immune response and reverses starvation-induced immunosuppression. Nature 1998;394:897-901.

6 Siegmund B, Sennello JA, Jones-Carson J, et al. Leptin receptor expression on $T$ lymphocytes modulates chronic intestinal inflammation in mice. Gut 2004;53:965-72.

7 Wada K, Nakajima A, Blumberg RS. PPAR- $\gamma$ and inflammatory bowel disease: a new therapeutic target for ulcerative colitis and Crohn's disease. Trends Mol Med 2001;7:329-31.

8 Buyse M, Berlioz F, Guilmeau S, et al. PepT1mediated epithelial transport of dipeptides and cephalexin is enhanced by luminal leptin in the small intestine. J Clin Invest, 2001;108:1483-94.

9 Alavi K, Schwartz MZ, Prasad R, et al. Leptin: a new growth factor for the small intestine. J Pediatr Surg 2002;37:327-30.

10 Siegmund B, Lehr HA, Fantuzzi G. Leptin: a pivotal mediator of intestinal inflammation. Gastroenterology 2002;122:2011-25.

11 Busso N, So A, Chobaz-Peclat V, et al. Leptin signaling deficiency impairs humoral and cellular immune responses and attenuates experimental arthritis. J Immunol 2002;168:875-82.

12 Faggioni $\mathbf{R}$, Jones-Carson J, Reed DA, et al. Leptin-deficient (ob/ob) mice are protected from $T$ cell-mediated hepatotoxicity: role of tumor necrosis factor a and IL-18. Proc Natl Acad Sci U S A 2000;97:2367-72.

13 Matarese G, Di Giacomo A, Sanna V, et al. Requirement for leptin in the induction and progression of autoimmune encephalomyelitis. J Immunol, 2001;166:5909-16.

14 Barbier M, Vidal H, Desreumaux $P$, et al. Overexpression of leptin mRNA in mesenteric adipose tissue in inflammatory bowel diseases. Gastroenterol Clin Biol 2003;27:987-91.

15 Cashman KD, Shanahan F. Is nutrition an aetiological factor for inflammatory bowel disease? Eur J Gastroenterol Hepatol 2003; 15:607-13.

16 Payne A. Nutrition and diet in the clinical management of multiple sclerosis. J Hum Nutr Diet 2001:14:349-57.

17 Kjeldsen-Kragh J, Haugen M, Borchgrevink CF, et al. Controlled trial of fasting and one year vegetarian diet in rheumatoid arthritis. Lancet 1991;338:899-902.

18 Fraser DA, Thoen J, Reseland JE, et al. Decreased $\mathrm{CD} 4^{+}$lymphocyte activation and increased interleukin-4 production in peripheral blood of rheumatoid arthritis patients after acute starvation. Clin Rheumatol 1999; 18:394-401.

19 Steinman L, Conlon P, Maki R, et al. The intricate interplay among body weight, stress, and the immune response to friend or foe. J Clin Invest 2003;111:183-5. 
Fatly liver

\section{Fatty liver, hypertension, and the metabolic syndrome}

\section{A M Diehl}

\section{The prevalence of fatty liver in non-obese non-diabetic hypertensive patients is at least twice that of the general population and may be related to increases in insulin resistance and body weight}

$\mathrm{T}$ he clinical significance of hepatic steatosis remains controversial. Long known to be common, ${ }^{12}$ fatty liver was once dismissed as an innocuous condition, particularly when discovered incidentally in individuals with normal serum aminotransferases. ${ }^{3-5}$ However, as discussed subsequently, emerging evidence challenges this old assumption by demonstrating strong associations between hepatic steatosis and other potentially life threatening diseases.

Reports that some alcohol abusers and non-alcoholic individuals with fatty livers eventually develop cirrhosis and succumb to "typical" complications of advanced liver disease are certainly concerning. ${ }^{3}{ }^{4-11}$ Moreover, evidence suggests a detrimental interaction between hepatic steatosis and other types of chronic hepatitis because several studies have identified fatty liver as an independent predictor of progressive liver fibrosis in patients with chronic hepatitis $\mathrm{C}^{12-14}$ and at least one study demonstrated that hepatic steatosis conveys an independent risk for hepatocellular carcinoma in this population. ${ }^{15}$ Hepatic steatosis is also associated with a poor response to antiviral therapy ${ }^{13}$ although this may be because it is strongly associated with obesity, which independently decreases the efficacy of hepatitis C treatment. ${ }^{16}$ In any case, there is no longer any doubt that having a fatty liver increases an individual's risk for advanced liver disease.

In addition, fatty liver is strongly associated with other disorders that are themselves major causes of morbidity and mortality. As mentioned earlier, fatty liver is often linked with obesity, ${ }^{17}$ a condition that significantly increases the risk of dying from any disease. ${ }^{18}$ Obesity, particularly visceral adiposity, is also an important component of the insulin resistance metabolic syndrome, a constellation of disorders (for example, dyslipidaemia, type 2 diabetes, and hypertension) that promote cardiovascular disease. ${ }^{19}$ The paper by Donati and colleagues ${ }^{20}$ in this issue of Gut, draws our attention to the relationship between fatty liver and hypertension [see page 1020].

Briefly, the authors of this study used abdominal ultrasonography to detect "bright" (that is, fatty) livers in hypertensive individuals who had normal liver blood tests and no obvious risk factors for hepatic steatosis. The study population was a relatively select subgroup of hypertensive individuals, given that $\sim 80 \%$ of the hypertension clinic population had at least one risk factor for fatty liver or hepatitis that excluded them from enrolment. Surprisingly, despite lacking all of the obvious risk factors for hepatic steatosis, $\sim 30 \%$ of the hypertensive individuals in the present study had fatty livers. These findings demonstrate that the prevalence of hepatic steatosis in non-obese nondiabetic hypertensive adults is at least twice the historical prevalence of fatty liver in the general adult populations ${ }^{1}$ and almost three times the prevalence of hepatic steatosis in the age and sex matched group of concurrent controls. Interestingly, although none of the subjects in the present study was obese or overtly diabetic, hypertensive individuals with fatty livers had higher glucose levels, body mass indices, and insulin resistance than hypertensive individuals without fatty livers. Controls with fatty livers also had higher fasting serum levels of insulin and glucose, and greater insulin resistance than controls without fatty livers, although both of the control groups had similar body mass indices.

These results are important because they complement and extend other evidence that correlates hepatic steatosis with insulin resistance. ${ }^{21}$ The strong association between these two conditions has tremendous clinical relevance. On one hand, it suggests that detection of fatty liver identifies an individual who is quite likely to have insulin resistance and hence should be evaluated for other disorders in the insulin resistance syndrome (for example, diabetes, hypertension, dyslipidaemia). On the other hand, it suggests that an individual with features of the metabolic syndrome should be screened for fatty liver disease.

Few would argue against more aggressive screening for diabetes, hypertension, and dyslipidaemia because effective treatment of these disorders is known to reduce subsequent morbidity and cardiovascular mortality. ${ }^{22-24}$ However, some may disagree with implementing more widespread screening for hepatic steatosis because there is, as yet, no direct evidence that reducing liver fat is beneficial. To address this concern, it is necessary to understand whether it is the hepatic lipid accumulation per se or the factor(s) that promote(s) hepatic steatosis that is/are to blame for the adverse clinical outcomes that occur in individuals with fatty livers. Studies in experimental animals, as well as in patients, suggest that both are probably involved because hepatic lipid metabolism interfaces with the interactive matrix of metabolic products, hormones, cytokines, and neurotransmitters that coordinates substrate utilisation with the energy requirements for maintaining tissue integrity. ${ }^{25-27}$ Fat accumulation within hepatocytes indicates that the master system for regulating energy homeostasis has malfunctioned. However, fatty liver is also more than a mere barometer of metabolic dysfunction because it triggers signals to normalise lipid levels in the liver. The latter may involve altering the activities of the cytokines, hormones, and neurotransmitters that regulate fat turnover in other tissues. As these regulatory factors are quite pleiotropic, collateral neurohumoral and immune dysfunction often ensue. Thus fatty liver is both a consequence of and contributor to the "dys"-metabolic insulin resistance syndrome. As such, it represents a reasonable therapeutic target.

The validity of this concept is supported by emerging evidence that various treatments (for example, lifestyle modifications, certain types of bariatric surgery, thiazolidinediones, metformin) that improve insulin resistance generally also improve hepatic steatosis. ${ }^{28}$ Thus our therapeutic armoury now includes reasonably effective weapons for these disorders. Questions remain however about when to deploy our "missiles". All therapeutic interventions incur some cost, and none is 100\% effective. For example, no currently available insulin sensitising therapy uniformly prevents (or reverses) features of the metabolic syndrome. ${ }^{28} 29$ 
Furthermore, even when untreated for insulin resistance, most individuals with fatty livers (or with hypertension, dyslipidaemia, or type 2 diabetes) live with these disorders for decades without experiencing significant hepatic or cardiovascular morbidity. ${ }^{90}$ Because the basis for interindividual differences in clinically significant outcomes of the metabolic syndrome is poorly understood, physicians are uncertain when to "attack" insulin resistance. Therefore, research is needed to characterise factors that modulate the natural histories of hepatic steatosis and other disorders, such as hypertension, that often develop in the context of insulin resistance. This information may help us to understand when treatments to enhance insulin sensitivity are necessary, as well as why these therapies sometimes fail to prevent end organ damage in individuals with the metabolic syndrome. In turn, this knowledge will permit us to select patients who are likely to achieve the greatest benefit from insulin sensitising therapy. If fatty liver is indeed a convenient marker for dangerous insulin resistance, then it will be important to determine if implementing efforts to improve insulin sensitivity when hepatic steatosis is diagnosed prevents dreaded consequences of the metabolic syndrome, such as cardiovascular disease, cirrhosis, and hepatocellular carcinoma.

\section{ACKNOWLEDGEMENTS}

This work was supported by 2R01 DK53792.

Gut 2004;53:923-924.

doi: 10.1136/gut.2003.037309

Correspondence to: Professor A M Diehl, The Johns Hopkins University, 912 Ross Building, 720 Rutland St, Baltimore, MD 21205, USA; amdieh|@jhmi.edu

\section{REFERENCES}

1 Bellentani S, Saccoccio G, Masutti F, et al. Prevalence of and risk factors for hepatic steatosis in Northern Italy. Ann Intern Med 2000;132:112-17.

2 Younossi Z, Diehl AM, Ong J. Nonalcoholic fatty lier disease: an agenda for clinical research. Hepatology 2002;35:746-52.

3 Powell EE, Cooksley GE, Hanson R, et al. The natural history of nonalcoholic steatohepatitis: $A$ follow-up study of 42 patients follow for up to 21 years. Hepatology 1990;1 1:74-80.

4 Teli $M$, James OF, Burt AD, et al. A natural history of nonalcoholic fatty liver: A follow-up study. Hepatology 1995;22:1714-19.

5 Falck-Ytter Y, Younassi ZM, Marchesini G, et al. Clinical features and natural history of nonalcoholic steatosis syndromes. Semin Liver Dis 2001;21:71-6.

6 Van Waes L, Lieber CS. Early perivenular sclerosis in alcoholic fatty liver: an index of progressive liver injury. Gastroenterology 1977;73:646-50.

7 Worner TM, Lieber CS. Perivenular fibrosis as precursor lesion of cirrhosis. JAMA 1985;254:627-30.

8 Nonomura A, Mizukami Y, Unoura M, et al. Clinicopathologic study of alcohol-like liver disease in non-alcoholics; non-alcoholic steatohepatitis and fibrosis. Gastroenterol Jpn 1992;27:521-8.

9 Matteoni C, Younossi ZM, McCullough A. Nonalcoholic fatty liver disease: A spectrum of clinical pathological severity. Gastroenterology 1999;116:1413-19.

10 Harrison SA, Torgerson S, Hayashi PH. The natural history of nonalcoholic fatty liver disease: a clinical histopathological study. Am J Gastroenterol 2003;98:2042-7.

11 Jepsen P, Vilstrup H, Mellemkjaer L, et al. Prognosis of patients with a diagnosis of fatty liver-a registry-based cohort study. Hepatogastroenterology 2003;50:2101-4.

12 Adinolfi LE, Gambardella M, Andreana A, et al. Steatosis accelerates the progression of liver damage of chronic hepatitis $C$ patients and correlates with specific HCV genotype and visceral obesity. Hepatology 2001;33:1358-64.

13 Monto A. Hepatitis $C$ and steatosis. Semin Gastrointest Dis 2002;13:40-6.

14 Hezode C, Lonjon I, Roudot-Thoraval F, et al. Impact of moderate alcohol consumption on histological activity and fibrosis in patients with chronic hepatitis C, and specific influence of steatosis: a prospective study. Aliment Pharmacol Ther 2003; 17:1031-7.
15 Ohata K, Hamasaki K, Toriyama K, et al Hepatic steatosis is a risk factor for hepatocellular carcinoma in patients with chronic hepatitis $C$ virus infection. Cancer 2003;97:3036-43

16 Bressler BL, Guindi M, Tomlinson G, et al. High body mass index is an independent risk factor for nonresponse to antiviral treatment in chronic hepatitis C. Hepatology 2003;38:639-44.

17 Clark JM, Brancati FL, Diehl AM. Nonalcoholic fatty liver disease. Gastroenterology 2002;122:1649-57.

18 Pi-Sunyer FX. The obesity epidemic: pathophysiology and consequences of obesity. Obes Res 2002;10(suppl 2):97-104S.

19 Lebovitz HE. The relationship of obesity to the metabolic syndrome. Int J Clin Pract Suppl 2003;134:18-27.

20 Donati G, Stagni B, Piscaglia F, et al. Increased prevalence of fatty liver in arterial hypertensive patients with normal liver enzymes: role of insulin resistance. Gut 2004:53:1020-23.

21 Marchesini G, Bugianesi E, Forlani G, et al Nonalcoholic fatty liver, steatohepatitis, and the metabolic syndrome. Hepatology 2003;37:917-23.

22 Szapary PO, Rader DJ. Pharmacological management of high triglycerides and low highdensity lipoprotein cholesterol. Curr Opin Pharmacol 2001;1:113-20.

23 Elliott WJ. Is fixed combination therapy appropriate for initial hypertension treatment? Curr Hypertens Rep 2002;4:278-85.

24 Ali Raza J, Movahed A. Current concepts of cardiovascular diseases in diabetes mellitus. Int J Cardiol 2003;89:123-34.

25 Large V, Arner P. Regulation of lipolysis in humans. Pathophysiological modulation in obesity, diabetes, and hyperlipidaemia. Diabetes Metab 1998:24:409-18.

26 Philipson LH. Beta-agonists and metabolism. $J$ Allergy Clin Immunol 2002; 110 S313-17.

27 Garg R, Tripathy D, Dandona P. Insulin resistance as a proinflammatory state: mechanisms, mediators, and therapeutic interventions. Curr Drug Targets 2003;4:487-92.

28 Angulo P. Current best treatment for nonalcoholic fatty liver disease. Expert Opin Pharmacother 2003;4:611-23.

29 Tadayyon M, Smith SA. Insulin sensitisation in the treatment of type 2 diabetes. Expert Opin Invest Drugs 2003;12:307-24.

30 Hoffmann IS, Cubeddu LX. Clustering of silent cardiovascular risk factors in apparently healthy Hispanics. J Hum Hypertens 2002 16(suppl 1):S137-41 